Indian and South Atlantic Oceans. This was well before Eduard Suess gave the name Gondwanaland to the supposed pre-Tertiary southern continent.

Work by C. Schuchert published in 1932 on the distribution of Tertiary fossils confirmed the conclusions established by Blandford from living forms. Schuchert similarly required land communications over some of the present oceanic areas, but demanded relatively small land bridges, thinking, as he said, that it would be "easier to sink smaller continentallike masses than larger ones".

Another, wholly different, explanation for the distribution of life has been elaborated in the last twenty-seven years, mainly by the late Alfred Wegener, who maintained that an ancient continental mass, which he named Pangæa, existed in the South Atlantic and Antarctic region and broke up during the Mesozoic period; that fragments of it drifted away to form most of South America, South and Central Africa, Madagascar, India and Australasia, taking with them their records of geological activities during Palæozoic times. This theory is thus assumed to account for the glaciation of lands like India which are in the northern tropics, as well as continents which are still south of the equator ; it explains, too, the correspondences between the Gondwana rocks of India and those on the southern continents.

Wegener's hypothesis, according to many geologists, is based on insufficient and often discordant data, whilst mathematicians assert that the mechanics involved in these horizontal movements of continental masses are quite impossible.
Following a suggestion made by R. H. Rastall in 1929 , it is now urged that discussion of the purely theoretical implications of this hypothesis should await the accumulation of geological data by work on the lines undertaken by A. L. du Toit in com. paring Africa and South America. Du Toit has demonstrated the remarkable duplication of geo. logical features between these two areas, from Lower Palæozoic, age by age, to Upper Mesozoic times. $\mathrm{He}$ has also noticed that when the formations vary in the usual way laterally, the variation eastward in Africa and westward in South America is generally greater than that between the corresponding formations on the opposed present shores, although these are now separated by the width of the South Atlantic. Du Toit reasonably concludes that the agreements are too frequently concordant to be regarded as fortuitous, and that the only explanation which best fits the facts is the assumption that these two continents were at one time near one another if they were not actually confluent continental masses.

If it be true that these continental masses have moved horizontally in late geological times away from one another, there is no reason why others should not have done so too, in spite of the cir. cumstance that no completely satisfactory explana. tion of the mechanics involved can be offered at present. Further work on the lines so ably undertaken by du Toit is now more necessary than mathematical criticism with insufficient quantitative data regarding the physical state of the earth's sub-crust under the continents and oceans.

\title{
Magnetic and Optical Properties of Crystals
}

$\mathrm{U}^{\mathrm{N}}$ NDER this title, Prof. K. S. Krishnan of the Indian Association for the Cultivation of Science (Calcutta) delivered three lectures in the Cavendish Laboratory, Cambridge, on April 26, 29 and 30. In the first lecture he dealt with recent studies of the diamagnetic properties of single crystals, particularly aromatic compounds. The method of deriving the principal susceptibilities of aromatic molecules by combining magnetic measure. ments with crystal structure determination was described and also the way in which molecular orientation may be predicted on the basis of magnetic measurements alone. A summary of Pauling's method of calculating the principal susceptibilities of any aromatic molecule was given. The experimental method for measuring anisotropy in magnetic susceptibility was demonstrated and also the remarkable property of graphite crystals both as they occur naturally and after exposure to potassium vapour or to oxidizing agents.

The second lecture was devoted to the recent work on paramagnetic crystals. Prof. Krishnan's study of the magnetic properties of $\mathrm{CuSO}_{4} .5 \mathrm{H}_{2} \mathrm{O}$ has confirmed the predictions concerning the ionic environment made on the basis of theoretical studies and has afforded a remarkable correlation of the magnetic properties with the details of the crystal structure. The influence of the co-ordination on the magnetic anisotropy of the cobalt ion is shown by the comparison of the susceptibilities of $\mathrm{CoSO}_{4} \cdot \mathrm{K}_{2} \mathrm{SO}_{4}$ $.6 \mathrm{H}_{2} \mathrm{O}$ with those of $\mathrm{Cs}_{3}\left[\mathrm{CoCl}_{4}\right] \mathrm{Cl}$. The former salt, in which the paramagnetic ion is six co-ordinated, is of great magnetic anisotropy, while the second salt, in which the cobalt is four co-ordinated, has a very small magnetic anisotropy. This result also confirms predictions made on the basis of other physical data. The study of very small magnetic anisotropy of certain manganese salts has made possible the prediction of the entropy of these substances at temperatures near to absolute zero-an important quantity in view of the use to which these salts are put in obtaining very low temperatures by adiabatic magnetization.

The third lecture dealt with the absorption and fluorescent spectra of certain aromatic compounds. Anthracene, naphthacene and chrysene have well. marked pleochroic characters. The absorption spectrum in the ultra-violet region has strong bands for rays vibrating in that principal plane which is most nearly parallel to the plane of the molecules, and weak bands for rays vibrating in that principal plane which is most nearly perpendicular to the planes of the molecules. Naphthacene is a common impurity in anthracene and chrysene, and even when only a few parts per million of the impurity are present a strong fluorescent spectrum is observed. This has the remarkable property of being strongly excited in one plane only, no matter what the relative orientation of the plane of vibration of the incident light. This plane, corresponding to the vibration of the strongly excited spectrum, is coincident with that principal plane which is most nearly parallel to the molecular planes. Some experiments on the photodissociation of potassium nitrate in ultra-violet light were also described. 